\title{
Fostering Existential Maturity to Manage Terror in a Pandemic
}

\author{
Linda Emanuel, MD, PhD, ${ }^{1}$ Sheldon Solomon, $\mathrm{PhD},{ }^{2}$ George Fitchett, $\mathrm{PhD},{ }^{3}$ Harvey Chochinov, MD, PhD, ${ }^{4,5}$ \\ George Handzo, MA, ${ }^{6}$ Tasha Schoppee, MSN, RN, ${ }^{7}$ and Diana Wilkie, PhD, RN, FAAN ${ }^{7}$
}

\begin{abstract}
Background: The COVID-19 pandemic has created an environment in which existence is more fragile and existential fears or terror rises in people.

Objective: Managing existential terror calls for being mature about mortality, something with which palliative care providers are familiar and in need of greater understanding.

Methods: Using a case to illustrate, we describe existential terror, terror management, and existential maturity and go on to outline how existential maturity is important for not only the dying and the grieving but for also those facing risk of acquiring COVID-19.

Results: Next, we describe how essential components in attaining existential maturity come together. (1) Because people experience absent attachment to important people as very similar to dying, attending to those experiences of relationship is essential. (2) That entails an internal working through of important relationships, knowing their incompleteness, until able to "hold them inside," and invest in these and other connections. (3) And what allows that is making a meaningful connection with someone around the experience of absence or death. (4) We also describe the crucial nature of a holding environment in which all of these can wobble into place.

Discussion: Finally, we consider how fostering existential maturity would help populations face up to the diverse challenges that the pandemic brings up for people everywhere.
\end{abstract}

Keywords: attachment; existential maturity; presence; psychic disconnection; terror management; trauma

\section{Introduction}

D URING TIMES of population-wide crisis, people take different paths; the crisis can promote descent into divisiveness and destructiveness or it can generate proactive cohesiveness that limits damage and augments learning and psychosocial resilience. We see in these extreme alternatives the playing out of two fundamentally different ways of responding to death. While humans all, by our nature, fear death, one approach is less emotionally equipped than the other is. We refer to the more equipped as existentially mature. For those providing care for the dying, finding ways to foster existential maturity is imperative. This article considers pragmatic and theoretical underpinnings of how people may be able to equip themselves with one of the main ingredients of palliative medicine-coming to terms with death-to help take a proactive, existentially mature approach. We use an anonymized case to illustrate how existential maturity worked for one person in a common situation during the spring of 2020 caused by the coronavirus pandemic.

\section{Case}

Kameron, at 65, was facing the COVID-19 pandemic alone in a small studio apartment in NY. He was in isolation both because he felt terribly ill, although he had been denied a COVID-19 test, and because of the shelter in place guidelines. His partner was stuck out of state since it began and the troubles in their decade-long relationship that had already been evident were leaving him feeling emotionally as well as physically isolated even after his physical symptoms lifted. Working as a musician and in the charity world until his organization "temporarily closed," Kameron had intense relationships in his work and personal life; people described him as

\footnotetext{
${ }^{1}$ Northwestern University, Chicago, Illinois, USA.

${ }^{2}$ Skidmore College, Saratoga Springs, New York, USA.

${ }^{3}$ Rush University Medical Center, Chicago, Illinois, USA

${ }_{5}^{4}$ Department of Psychiatry, University of Manitoba, Winnipeg, Manitoba, Canada.

${ }^{5}$ CancerCare Manitoba, Winnipeg, Manitoba, Canada.

${ }^{6}$ Health Services Research and Quality at HealthCare Chaplaincy Network, New York, New York, USA.

${ }^{7}$ Center for Palliative Care Research and Education at University of Florida, Gainesville, Florida, USA.

Accepted June 9, 2020.
} 
talented, driven, loving, overbearing, and needy. His parent's traumatic history as war refugees and the loss of his hemophiliac wife and child to AIDS had greatly defined his life. Now Kameron's panic attacks, not present since the 80s when his family was ill and dying one by one, returned. Kameron had been engaging in existential therapy with a psychoanalyst for five years. With this new situation, Kameron met with his therapist, now by teleconference, between four and seven times a week. During several weeks of this intensive therapy work, Kameron relived in a new way his old and recrudescent fear of death and his anger at his "inherited trauma" as he called it. He waded through the intense hurt at feeling abandoned and "psychically killed," by his partner's distance at this most difficult time. In one session that seemed inwardly transformative, Kameron talked of how heavy he feels when going to bed, and he recalled how he felt when his mother seemed never to meet his gazeeven after his father had "reamed" him yet again. His therapist stayed with Kameron's feeling, offering words that mirrored his sensation, and then observed quietly, looking directly through the video camera at Kameron's face, how different it would have been if his mother had just looked up and smiled. Kameron wept and filled with a sense of spiritual lifting, as he later called it. Kameron also broke through to a new level of comfort being himself, being less reliant on his partner to feel safe and connected, and found new connections with friends and colleagues who seemed to come from far and long ago, checking on one another by all kinds of e-connections to see how they were doing. He was able to see how others saw him as overbearing and needy, and understood more of what caused the troubles between him and his partner. He made some of what he felt was his best music yet and redirected his charity work, keeping the line of communication open with his partner as both of them reached for a new state of what Kameron called "spiritual maturity."

To draw on this case for understanding, we first acknowledge that the situation could have gone quite differently. Kameron could have spun out into experiencing his partner as abandoning and preemptively ended the relationship; he could have so desperately needed company that he might have failed to keep social distancing; he could have become dangerously depressed and self-harmed. What underlies these two types of pathways and how did Kameron avoid a destructive one?

\section{Existential terror}

Human awareness of death can give rise to potentially debilitating existential terror. ${ }^{1,2}$ Fear of death seems to be written into the human makeup. We can find it in the earliest archeological evidence of human responses to death and in every culture and in everyday popular movies and videogames. ${ }^{3,4}$ Freud posited concepts of the death drive, although they remained ill defined. ${ }^{5}$ Also, Becker argued with great clarity that death anxiety drives the way in which we all live essentially all the time. ${ }^{6} \mathrm{He}$ described persuasively that feelings aroused by awareness of dying are "managed" by embracing cultural worldviews that afford a sense that we are valuable participants in a meaningful universe.

\section{Managing existential terror}

The fundamental observation that when intimations of mortality are aroused, as in the aftermath of 9/11 and now in the pandemic, people generally respond by bolstering faith in their cherished beliefs, and sense of self-worth predicates terror management theory. ${ }^{7}$ Some individuals, however, by virtue of genetic predisposition, neuroanatomical or biochemical abnormality, or overwhelming stress, perhaps amplified by previous trauma, are unable to cope with death anxiety in this manner and resort to defensive reactions that Yalom described as "clumsy modes of dealing with terror.", 8

Yalom also believed that such modes were avertible and toward that end, he designed group, self-help, and psychodynamic approaches, in particular existential psychotherapy. We understand many other widely available approaches, some of which have existed for centuries, probably also afford less destructive and even very creative modes. All major and enduring religions and other belief systems have ways of thinking and behaving about death that are evocative and embracing in their ritual, music, texts, tenets, and more. 9,10 Providing support for gravely ill patients, and their loved ones, has long been a central focus of health care chaplains. ${ }^{11}$ Medical institutions offer the full range of mental health services to people facing death. Many recently have been offering free mental health services to their frontline providers, including when a colleague succumbs to COVID-19, and using collective rituals such as the sacred pause, use of poetry, and live music. Interventions designed to enhance and preserve dignity for those near death such as Dignity Therapy and Meaning Centered Care bring comfort to patients and family members, and perhaps health care providers too, and deserve further study for their possible impact on modes of responding to death. ${ }^{12-16}$ These novel therapies are designed to reignite a sense of meaning and purpose within the context of approaching death, and at their core, are meant to convey that the life that was, the life that is, and the life that will soon be mourned matters. Perhaps most important and most immediately available is the comfort of family and friends who can help one another talk or be with the difficult realities in the security of one another's care. ${ }^{17}$

\section{Existential maturity}

We observe that all these approaches have the potential to not only mitigate the terrible feelings and possibly destructive responses aroused by death but to also foster a generative contrasting outcome. A proposed term for this is existential maturity.

Existential maturity can be thought of as a state, stage, process, or ability in which death anxiety is coped with well. We think of it as a capacity in which people can appreciate our mortal condition without being overwhelmed by fear and loss. They can take in the goodness of life in a way that strengthens us even in severely disabled conditions. ${ }^{18,19}$ It is a fluid state rather than linear or static in that no one seems to simply "arrive and stay there," but rather people oscillate within a range-of-feeling states. ${ }^{20}$ However, it is a reliable and recognizable state in that it allows a person to face mortality and do the work of dying and/or grieving without spinning out into panic attacks, traumatizing terror, or depression, such as Kameron was re-experiencing, that interferes with subjective and intersubjective life. ${ }^{21}$ Perhaps people can arrive at a stage in life when the state of existential maturity is a reliably present capacity. ${ }^{22}$ Perhaps it can occur as part of progressive development as in Erikson's life stages. ${ }^{23}$ Or perhaps it can be part of a personality trait or developed by exposure, even perhaps as part of 
post-traumatic growth, or in relationship. We believe all these routes occur for young and old alike and that existential maturity can be found described in many literary and artistic, psychological, and spiritual works, and in everyday observations.

\section{Who Needs Terror Management and Existential Maturity?}

Death's salience is suddenly all around. ${ }^{24}$ The risk of destructive responses to it is high. In which arenas can existential maturity help in this time of crisis? We suggest some here and some more in the final section of this article.

\section{Comfort for the dying and grieving}

Existential maturity in a person who is dying or facing loss entails creating and sustaining experiences of connectedness that gives continuity through one another. The dying vest their legacy and shared narratives in those remaining. Among their intimate relationships, they vest a piece of their selves. Those saying goodbye receive those gifts and live on with them. That is the connectedness that makes dying tolerable, and even an experience of unparalleled love. For those with a sense for life beyond our own, there is a feeling of connection to the greater universe and across time. Palliative care provides the setting, or holding environment to use Winnicott's concept, in which people can achieve that state as fully as possible and do their last life work. ${ }^{25-27}$ Those who provide care must confront their own mortality to be able to create a holding environment that fosters existential maturity. However, palliative care is not alone; other settings such as family and community can provide similar holding environments. Much of psychotherapy, including but not limited to the method in particular known as existential therapy that Kameron was receiving, also provides settings for developing existential maturity. $6,28,29$

The circumstances of COVID-19 have made a particularly powerful assault on relatedness, on human dignity, on myriad previously basic social structures. People are forced to be alone when mortally ill, perhaps even when dying, and to grieve alone. The part of death that is most terrifying for many is the process of dying; the disintegration from a living, relating, loving, unique human being. Indeed, conceptions of hell are often a never-ending state of torment. ${ }^{30}$ Nonexistence may be unimaginable but is less terrible for many. So it is during dying when presence is most needed. Presence of loved ones allows for passage of integral living among them to the survivors. Preserving the narrative or relational integrity of a person's life in the hearts and minds of loved ones can maintain dignity in the face of death; presence and by legacy statements that are exchanged are among the ways that affirm this. The creative ways in which nurses and others have allowed family to connect by phone or video or leave messages are essential to allowing people access to and bolstering of dying person's existential maturity, allowing a sense of connection as they pass. ${ }^{31}$ Prioritizing other ways is important, because, as we describe below, relatedness in the setting of the reality of death seems to be an essential ingredient in coping well with death; it is often the last important thing that a dying person reaches for.

This essential place of relatedness is also true for the grieving. The cocreated part of the grieving person, the part that intertwines with the deceased, has to metaphorically bleed, make a protective layer, and heal with new cocreations with other people. ${ }^{32}$ Traditionally, the process starts immediately with managing the body and making funeral arrangements. Now, virtual funerals and related rituals have become widespread. Some have, horrifically, been assigned to temporary mass containers or graves or removed for immediate cremation, leaving family with little chance to manage the "to dust" transition in a way that holds on to their departed member's human dignity. Additional ways, previously more associated with honoring the fallen in war, have emerged. $^{12}$ Especially in the absence of community remembrance events that social distancing may limit, more is still necessary to promote and preserve the connection between people over their deaths that is essential for existential maturity.

\section{An anchor when facing mortal risk}

Existential maturity is highly relevant for those facing risk of dying as well as for people and their families with known life-limiting illness. Currently, the COVID-19 pandemic churns through the global population, which includes our frontline health care workers, essential workers, those in quarantine or similar isolation, the unemployed, the volunteers, the disabled, and more.

Kameron's case is germane. He needed to reinforce his growing existential maturity when faced with his experience of isolation. Isolation had brought back his experiences of feeling abandoned and unable to "pull himself together" that came from his childhood and his lost loves. He had already worked through that experience of psychic deadness in his therapy. Now, Kameron again worked through the reality of mortality, sitting with the aloneness and feelings of fragmentation, and discovering a kind of fundamental company, first with his therapist and then with others, in that experienced wasteland. With that connection in the face of mortality or felt nothingness, instead of fear, Kameron eventually felt touched. With that connectedness, Kameron was able to resynthesize his sense of self and coherence and make use of old and new connections that were more mature, life affirming, and creative. He found, or refound, his existential maturity. Kameron was able to experience his mortal limitations and those of others he needed, and from this experience of "psychic death" to reach a more mature way of connecting with people that was less anxious. In similar ways, so too can frontline workers and others find their own more mature way. Kameron received existential therapy. Others will find different resources-whether those noted above or others-to aid theirs.

\section{Mitigating trauma}

Covid-19 has brought harrowing experiences to many more than those it has killed. People have reason to fear. Frontline health care and essential workers and their families, people who were deprived of last goodbyes and funerals, massive numbers facing unexpected unemployment, people dealing with abuse during required confinement in the home, and more are all at risk of at least burnout. ${ }^{33}$ Many have already sustained traumatic impact. The consequences of the harrowing experiences may be long term and for some even lethal. $^{34}$ As yet less prominent features such as social 
instability and food insecurity may grow and result in trauma for many as well.

Trauma, by its nature, tends to make people shut down, dissociate, and sometimes later act out as unmanageable feelings burst forth; such is the reality when experiences are intolerable and not digestible. Enough is now known about trauma that it appears clear that trauma can be from a singular or recurrent "micro" event/s and that it is essentially a twopart phenomenon: the traumatizing event/s and the responses of others to it that follow the event/s. ${ }^{35}$ Some who suffer trauma appear to be more resilient than others. Responses to the traumatized person that validate their experience and share the processing of it help. ${ }^{36}$

We think that existential maturity is a resilient state that mitigates the impact of potentially traumatizing events or circumstances, and that existential psychotherapy is one among other responses that can help a person process trauma. The case of Kameron is an example of this; therapy helped him come to terms with the impact of his early trauma and the reactivation of traumatizing experiences in the face of COVID-19 restrictions. The main feature that was processed was the reality of mortality and the related states of aloneness. The main experience that allowed the processing was experiencing it in the presence of an understanding other with whom there is an affective meeting. For Kameron, this reality once again became only one among other features of life's conditions that was motivating and no longer so terrifying and triggering.

\section{Essential Ingredients in Attaining Existential Maturity}

How does it happen that our own death and that of people we love and depend on can become something that, while far from wanted, is also not so alarming that it interrupts living or functioning under stress? We see some key features.

\section{Psychic disconnection is experienced as dying}

Disconnection from what Kohut called a self-object or an essential other and some forms of dissociation from parts of ourselves constitute a kind of psychic death. ${ }^{37,38}$ The term is often used to describe a person's traumatization. We use it in a broader way. We include this kind of disconnection as the experience state that is also at the base of many states of depression. It is a feeling so bad that some people would sooner chose physical death over that state. For many, physical death is much less anxiety provoking than the experience of losing connection. We are aware that many consider the agony of separateness to be different from death anxiety. However, when it comes to developing existential maturity, we purposefully connect these two.

Unlike physical death, this kind of psychic death seems to occur in degree and it seems to be evident in different aspects of the psyche. Children may respond with a little of their own deadness feeling to a parent figure who is a little depressed, and that little deadness may be retained into adulthood. A traumatic experience of loss may leave the survivor feeling half-alive. ${ }^{39}$ Chronic emotional absence of a sole available parent figure may leave a person schizoid or split into different personas. ${ }^{40}$ Perhaps the fully psychically dead yet physically alive person is catatonic.

We recognize this experience is much like the feeling of fragmenting, the falling from the embrace of person-to- person relatedness that Winnicott and others describe. ${ }^{41} \mathrm{We}$ see it as so closely related to the feeling of disintegrating during the dying process that it may be or may as well be the same. From this perspective, it makes sense that people in existential, analytic, or other dynamic treatment often find that when they can find, feel, and share that feeling it transforms both the relationship to the originating traumatic event/ $s$ and their relationship to mortality. Death salience becomes less alarming; it transforms into an awareness that heightens meaning, awe, or preciousness and motivates meaningful and often more related living.

This occurred most strongly for Kameron in the session in which he remembered his deadness and how it was related to his mother's lack of presence with him-something he described in her lack of eye contact when he tried to connect with her and especially when he needed comfort after being "reamed out" by his father. What made it lift rather than being just another painful revisitation of the feeling was experiencing it with another when that other could empathically share his feeling. He had been met by an other in that deeply essential existential way.

\section{Attachment and connection}

The nature and significance of this kind of deeply meaningful meeting require considering a second key feature: a person's relationships. Clinical experience suggests that a person's dying journey (their own or another's) is influenced by their attachments to people. Attachments are never perfect but they can be functional. When attachments are disturbed, people can nonetheless have made something manageable out of those relationships and have some availability for better functioning attachments. Often, the prospect of death prompts remarkable availability for new kinds of attachment; it appears to be an urgent matter when death seems close or newly relevant.

Attachment theory has convincingly set out how the nature of our attachments in early life influences attachments for the rest of our lives. ${ }^{42}$ An early secure bond between parent figure and child corresponds to children with curiosity and ease in transitioning to various kinds of additional relationships. Different, less secure attachment styles have been described-anxious, dismissive, and so on-and these correspond with more complicated and defended ways of exploring the world and making subsequent relationships. ${ }^{43}$ Apparently, this attachment or connection allows the feelings that come with exploration-fear, elation, surprise, puzzlement, attraction, disgust, and so on-to occur without being overwhelmed. Child observation studies support that this kind of development of internal self structure, including the capacity for "affect management," possible because of the parent figure. ${ }^{44}$ The infant appears to learn from the parent figure how to "metabolize" the essential existential fear of being separated from birth, and the child continues to learn how to recognize and navigate all kinds of sensations thereafter. Psychologists and others widely recognize the panoramic influence of this style on people's approach to living and relating well beyond childhood into the rest of their lives. Attachment style seems to characterize most people's relational life.

In light of this, a connection between fear of death and attachment style, or ways of relating, which otherwise might 
seem an odd claim indeed, seem more likely. ${ }^{45}$ Relational and existential maturity may be closely connected. This is consistent with well-known and striking studies demonstrating that separating baby primates from their mother causes severe damage or death despite having food and shelter. ${ }^{46}$ It seems people come to terms with absent connection from early times through the gradual experience of separation within understanding, holding, loving relationships. It seems premature unrelieved absence prevents relational and existential maturation.

A persuasive way of understanding what worked for Kameron in his therapy is the following. He had experienced the relational absence of his mother in childhood. In therapy, he was able to go back in remembered experience (his mother's absent gaze), find its relation to daily present lived experience (feeling heavy before sleep), and re-experience it with a metabolizing other in the form of the therapist (with the met gaze). He could take in the reality but now with a sense of connection as if the therapist were for a moment his mother.

Going a step further with this way of thinking makes sense. For those who tragically experienced a depressed or emotionally unavailable parent figure without any available substitute, their very early disconnection will leave the child to grow up with a pervasive sense of psychic death or numbness and a distorted need for connection. Circumstances of isolation or separation may well trigger a resurgence of both. This was the case for Kameron. Addressing that resurgence allows an additional step in existential maturation.

\section{Meeting and maturation}

How do these two experiences come together to create maturation? It seems that the same kind of thing that works between a parent figure and child works in those facing death. In children, it works to create secure attachment and resilience in the face of challenges that come with exploration. Among those facing dying, it can work to create existential maturity. Indeed, perhaps they are part of the same line of development.

Meeting Kameron with understanding presence and perhaps a touch of guidance or reassurance resolved his existential void almost as powerfully as a little light can chase away a room full of darkness. Nothing about the reality of human finitude is changed except the possibility of that kind of connection.

Thinking again of the developing child: when that kind of connection of being met by a parent figure can be held in mind, a child has the ability to hold it across time and space. The child can explore, be curious. The more the child does so and returns with feelings (fear, anger, sadness, excitement, joy, etc.) to the parent figure who then helps the child with understanding and guidance, the more the child can feel and use the feelings without being unanchored.

So too, as we understand it, is the case with existential maturity. In our case, it was Kameron. Kameron was able to hold the connection with his therapist across time and space and to feel deeply the absence without being unanchored. The experiential knowledge of connection made it possible to contemplate and experience absence. Being able to contemplate and experience absence with the knowledge of connection probably is a good enough description of existential maturity.

This process is a remarkable feature of the human psyche that is described but poorly understood. It appears that the experience of recognizing something in oneself, of knowing it in relationship with another, seems to set in motion a process of adapting to it. ${ }^{47}$ Psychotherapists, chaplains, and nurses make use of this innate ability routinely. It appears that the adaptation occurs best in relationship with someone-a therapist, a health care provider, a friend, a parent, a partner. Perhaps it occurs only in relationship with another, even if that other is currently present only in the mind.

It does not happen all in one moment. Although a mutative moment might occur, repeating and working through take time. ${ }^{48,49}$ Maturation comes from wading through the metaphoric mud, oscillating from dread to acceptance with a sense of having been met, and thence toward a steady state of manageable oscillations that allow feeling deeply without being unmoored. ${ }^{20}$

\section{Holding environment and presence}

We have described elsewhere the nature of the holding environment that fosters development of all kinds and existential maturity in particular. From the hovering, even attention, the deep understanding, and cocreation of meaning that the therapeutic frame fosters, to the presence of someone with whom creative exploration occurs, the person can create attachment, feel grief, and internalize the new relationship. New relating becomes possible, and eventually, separation and moving on. ${ }^{19,27}$

In addition, we believe a meeting presence is necessary; a present connection between the suffering person and someone. People tend to experience that kind of connection as love, but not always. In the personal setting, it may be love more often than not. In the psychotherapeutic setting, it may be transference love. Or in the medical setting, it is care but not love. Whatever we call it, once is usually not enough. With Kameron, different iterations of that kind of meeting in the darkness occurred with each dark moment, each relevant dream, and each daily challenge of aloneness. What was changing for Kameron, and we think that would be similar for others, is the meeting while experiencing absence. Perhaps this is what Winnicott described as the experience of being alone together. ${ }^{50}$

A holding environment that fosters existential maturity does not need to come from psychotherapy. It can come from art, sports, clergy, family, some forms of popular culture, or a blend of many such sources. Importantly, for palliative medicine to do its part, we believe palliative care clinicians, along with all health care providers tending to the needs of the dying, must be provided effective training that promotes existential maturity. This is necessary to allow them to provide the holding environment that the patients and family members need. Furthermore, palliative medicine should consider what service features are most conducive to enabling existential maturity in providers and the population served; perhaps dynamic therapy for family caregivers, group therapy, Balint groups for palliative medicine, or other features will be considered and evaluated. ${ }^{51}$

\section{Larger Implications}

For as profound and panoramic a situation as the current pandemic and its consequences, we think it likely that quantum changes will be necessary and inevitable in the way people live. We believe that existential maturity in the population is a necessary or at least helpful state for creatively 
responding to these crises, preserving what is important and recreating in new ways. A healthy dose of existential maturity would likely bring resilience and renewal where otherwise frontline workers could burn out very fast or experience unmitigated traumatization, whether by experiencing inequities or other suffering. ${ }^{52}$ This is already happening in communities where many people have died, including disproportionately, or are facing other consequences of the pandemic. ${ }^{53}$ In the communities of mental health providers and spiritual counselors, we observe that people are leaning heavily on their own existential maturity and on one another and on their sources of resilience during their work and own life in this pandemic. ${ }^{54,55}$

Even more broadly, in a world responding to climate change, human survival will require coordinated efforts by cognitively nimble and emotionally intelligent individual and state actors willing to explore a variety of political, economic, technical, and religious approaches to fostering a sustainable future. Many predict that conflicts over natural resources will accelerate, economic inequality and instability escalate, and political volatility intensify; this means that there will likely be a commensurate increase in death anxiety in people. With this natural mortality salience induction, research suggests we should anticipate alienation among people and warmongering, alienation from nature and assertive extraction of resources from the environment, and defensive avoidance in distracted activities, including use of substances, social media, and such. Perhaps, however, existential maturity will allow Albert Camus to be correct in his observation in The Plague that "we learn in time of pestilence...that there are more things to admire in men than to despise." 56 Also, while it may be far-fetched to claim that coming to terms with death will make anything possible, perhaps it can tip the balance and, as Ernest Becker hoped, "introduce just that minute measure of reason to balance destruction." 6

\section{Acknowledgment}

We thank Duncan Hollomon, JD, $\mathrm{PhD}$, for his insightful comments.

\section{Funding Information}

This research was made possible by Grant Number 1R01CA200867 from the National Institutes of Health (NIH), National Cancer Institute (NCI). The information in this article is solely the responsibility of the authors and does not necessarily represent the views of the NIH or NCI. The final peer-reviewed manuscript is subject to the NIH Public Access Policy.

\section{Author Disclosure Statement}

No competing financial interests exist.

\section{References}

1. Greenberg J, Koole SL, Pyszczynski T: In: Greenberg SL, Kool SL, Pyszczynski T (eds): Handbook of Experimental Existential Psychology. New York: Guilford Press, 2004.

2. Routledge C, Vess M: In: Routlege C, Vess M (eds): Handbook of Terror Management Theory. Amsterdam: Elsevier Academic Press, 2019.

3. Anderson JR, Biro D, Pettitt P: Evolutionary thanatology. Philos Trans R Soc Lond B Biol Sci 2018;373.
4. Moore CC, Williamson JB: The universal fear of death and the cultural response. In: Handbook of Death and Dying. London: Sage Publications, Inc., 2003.

5. Freud S: The Ego and the Id. The Standard Edition of the Complete Psychological Works of Sigmund Freud, Volume XIX. London: Hogarth Press, 1923, pp. 1923-1925.

6. Becker E: The Denial of Death. New York, NY: Simon \& Schuster, 1973.

7. Solomon S, Greenberg J, Pyszczynski T: The Worm at the Core: On the Role of Death in Life. New York, NY: Random House, 2015.

8. Yalom ID: Existential Psychotherapy. New York, NY: Basic Books, 1980.

9. Bregman L: Death and Dying in World Religions. Dubuque: IA Kendall Hunt Publishing, 2009.

10. Bowker J: The Problem of Suffering in the Religions of the World. Cambridge, UK: Cambridge University Press, 1970.

11. Steve Nolan: Spiritual Care at the End of Life: The Chaplain as 'Hopeful Presence.' London: Jessica Kingsley Publishers, 2012.

12. Kapoor S, Morgan CK, Siddique MA, Guntupalli KK: "Sacred Pause" in the ICU: Evaluation of a ritual and intervention to lower distress and burnout. Am J Hosp Palliat Care 2018;35:1337-1341.

13. Petrucci N: Beyond bleeps and alarms: Live music by the bedside in the ICU. Intensive Care Med 2018;44:22822283.

14. Weiser B: These Are the Bedside Concerts Comforting Virus Patients. New York Times, 2020.

15. Chochinov HM: Dignity Therapy: Final Words for Final Days. New York, NY: Oxford University Press, 2011.

16. Breitbart W, Rosenfeld B, Pessin H, et al.: Meaningcentered group psychotherapy: An effective intervention for improving psychological well-being in patients with advance cancer. J Clin Oncol 2015;33:749-754.

17. Glover T, Parry D: A third place in the everyday lives of people living with cancer: Functions of Gilda's Club of Greater Toronto. Health Place 2009;15:97-106.

18. Emanuel L, Scandrett KG: Decisions at the end of life: Have we come of age? BMC Med 2010;8:57.

19. Emanuel LL, Reddy N, Hauser J, Sonnenfeld SB: "And Yet It Was a Blessing": The case for existential maturity. J Palliat Med 2017;20:318-327.

20. Jackson VA, Jacobsen J, Greer JA, et al.: The cultivation of prognostic awareness through the provision of early palliative care in the ambulatory setting: A communication guide. J Palliat Med 2013;16:894-900.

21. Scalabrini A, Mucci C, Esposito R, et al.: Dissociation as a disorder of integration-On the footsteps of Pierre Janet. Prog Neuropsychopharmacol Biol Psychiatry 2020;101: 109928.

22. Richo D: How to Be An Adult: A Handbook on Psychological and Spiritual Integration. New York: Paulist Press, 1991.

23. Erikson EH: The Life Cycle Completed. London: Rikan Enterprises Ltd., 1982.

24. Johns Hopkins University \& Medicine Coronavirus $\mathrm{Cu}-$ mulative Cases. https://coronavirus.jhu.edu/data/cumulativecases (Last accessed April 28, 2020).

25. Winnicott DW: The theory of the parent-infant relationship. Int J Psychoanal 1960;41:585-595.

26. Winnicott DW: Holding and Interpretation. London: The Hogarth Press, 1986.

27. Emanuel L, Brenner KO, Spira N, et al.: Therapeutic Holding. J Palliat Med 2020;23:314-318. 
28. Schimmenti A, Billieux J, Starcevic V: The four horsemen of fear: An integrated model of understanding fear experiences during the Covid-19 pandemic. Clin Neuropsychiatry 2020;17:41-45.

29. Pargament K: Spiritually Integrated Psychotherapy. New York, NY: Guilford Press, 2007.

30. Dante A, Musa M: Dante's Inferno. Bloomington: Indiana Indiana University Press, 1971.

31. Wakam GK, Montgomery JR, Biesterveld BE, Brown CS: Not dying alone-Modern compassionate care in the Covid-19 pandemic. New Engl J Med 2020. DOI: 10.1056/ NEJMp2007781

32. Corless IB, Limbo R, Bousso RS, et al.: Languages of Grief: A model for understanding the expressions of the bereaved. Health Psychol Behav Med 2014;2:132-143.

33. Rushton $\mathrm{CH}$, Batcheller J, Schroeder $\mathrm{K}$, Donohue P: Burnout and resilience among nurses practicing in highintensity settings. Am J Crit Care 2015;24:412-420.

34. Watkins A, Rothfeld M, Rashbaum WK, Rosenthal BM: Top E.R. Doctor Who Treated Vius Patients Dies by Suicide. New York Times, 2020.

35. Southwick SM, Charney DS: Resilience: The Science of Mastering Life's Greatest Challenges. Cambridge: Cambridge University Press, 2012.

36. Stolorow RD: Autobiographical and theoretical reflections on the "Ontological Unconscious." Contemp Psychoanal 2006;42:233-241.

37. Kohut H: How Does Psychoanalysis Cure?. Chicago: University of Chicago Press, 1984.

38. Bollas C: Melville's lost self: Bartleby. Am Imago 1974; 31:401-411.

39. Frankel JB: Ferenczi's trauma theory. Am J Psychoanal 1998;58:41-61.

40. McWilliams N: The woman who hurt too much to talk: Unconventional psychoanalytic therapy with a deeply schizoid woman. Fort Da 2006;12:9-25.

41. Winnicott DW: Fear of breakdown. Int J Psychoanal 1974; 1:103-107.

42. Bowlby J: The nature of the child's tie to his mother. Int $\mathbf{J}$ Psychoanal 1958;39:350-373

43. Beebe B, Jaffe J, Markese S, et al.: The origins of 12-month attachment: A microanalysis of 4-month mother-infant interaction. Attach Hum Dev 2010;12:3-141.

44. Mikulincer M, Shaver PR: Enhancing the "Broaden and Build" Cycle of attachment security in adulthood: From the laboratory to relational contexts and societal systems. Int $\mathbf{J}$ Environ Res Public Health 2020;17:2054.

45. Mikulincer M, Florian V, Hirschberger G: The existential function of close relationships: Introducing death into the science of love. Pers Soc Psychol Rev 2003;7:20-40.

46. Harlow HF, Dodsworth RO, Harlow MK: Total social isolation in monkeys. Proc Natl Acad Sci USA 1965;54: 90-97.

47. Bion WR: The psycho-analytic study of thinking. Int $\mathrm{J}$ Psychoanal 1962;43:306-310.

48. Strachey J: The nature of the therapeutic action of psychoanalysis. Int J Psychoanal 1934;15:127-159.

49. Freud S: Remembering, Repeating and Working Through (Further Recommendations in the Technique of Psychoanalysis II) Vol. XII. London: Hogarth Press, 1914.

50. Winnicott DW: The maturational processes and the facilitating environment: Studies in the theory of emotional development. Int Psychoanal Lib 1965;64:1-276. London: The Hogarth Press and the Institute of Psycho-Analysis.

51. Robert M: Balint groups: A tool for personal and professional resilience. Can Fam Physician 2012;58:245.

52. Puyat JH, Leclerc A, Song A, et al.: Exposure to deaths and dying and risks of burnout among long-term care staff: A cross-sectional survey. Palliat Med 2019;33717-720.

53. Brooks RA: African Americans struggle with disproportionate COVID death toll National Geographic. April 24, 2020.

54. Southwick SM, Charney DS: The science of resilience: Implications for the prevention and treatment of depression. Science 2012;338:79-82.

55. Halifax J: Standing at the Edge: Finding Freedom Where Fear and Courage Meet. New York, NY: Flatiron Books, 2018.

56. Camus A: The Plague. New York, NY: Vintage Books, 1948.

Address correspondence to:

Linda Emanuel, MD, PhD

Northwestern University

750 N Lake Shore Drive

Chicago, IL 60208-0001

USA

E-mail: 1-emanuel@northwestern.edu 